\title{
Imaging, Behavior and Endocrine Analysis of "Jealousy" in a Monogamous Primate
}

\section{OPEN ACCESS}

Edited by:

Alexander G. Ophir,

Cornell University, United States

Reviewed by:

Jason Richard Yee,

Northeastern University, United States

Eduardo Fernandez-Duque,

Yale University, United States

*Correspondence:

Karen L. Bales

klbales@ucdavis.edu

Specialty section:

This article was submitted to Behavioral and Evolutionary Ecology,

a section of the journal

Frontiers in Ecology and Evolution

Received: 23 June 2017

Accepted: 19 September 2017

Published: 19 October 2017

Citation:

Maninger N, Mendoza SP, Williams DR, Mason WA, Cherry SR, Rowland DJ, Schaefer T and Bales KL

(2017) Imaging, Behavior and Endocrine Analysis of "Jealousy" in a Monogamous Primate.

Front. Ecol. Evol. 5:119. doi: 10.3389/fevo.2017.00119

\begin{abstract}
Nicole Maninger ${ }^{1}$, Sally P. Mendoza ${ }^{2}$, Donald R. Williams ${ }^{2}$, William A. Mason ${ }^{2}$, Simon R. Cherry ${ }^{3,4}$, Douglas J. Rowland ${ }^{4}$, Thomas Schaefer ${ }^{1}$ and Karen L. Bales ${ }^{1,2 *}$

${ }^{1}$ California National Primate Research Center, University of California, Davis, Davis, CA, United States, ${ }^{2}$ Department of Psychology, University of California, Davis, Davis, CA, United States, ${ }^{3}$ Department of Biomedical Engineering, University of California, Davis, Davis, CA, United States, ${ }^{4}$ Center for Molecular and Genomic Imaging, University of California, Davis, Davis, CA, United States
\end{abstract}

Understanding the neurobiology of social bonding in non-human primates is a critical step in understanding the evolution of monogamy, as well as understanding the neural substrates for emotion and behavior. Coppery titi monkeys (Callicebus cupreus) form strong pair bonds, characterized by selective preference for their pair mate, mate-guarding, physiological and behavioral agitation upon separation, and social buffering. Mate-guarding, or the "maintenance" phase of pair bonding, is relatively under-studied in primates. In the current study, we used functional imaging to examine how male titi monkeys viewing their pair mate in close proximity to a stranger male would change regional cerebral glucose metabolism. We predicted that this situation would challenge the pair bond and induce "jealousy" in the males. Animals were injected with $\left[{ }^{18} \mathrm{~F}\right]$-fluorodeoxyglucose (FDG), returned to their cage for $30 \mathrm{~min}$ of conscious uptake, placed under anesthesia, and then scanned for $1 \mathrm{~h}$ on a microPET P4 scanner. During the FDG uptake, males $(n=8)$ had a view of either their female pair mate next to a stranger male ("jealousy" condition) or a stranger female next to a stranger male (control condition). Blood and cerebrospinal fluid samples were collected and assayed for testosterone, cortisol, oxytocin, and vasopressin. Positron emission tomography (PET) was co-registered with structural magnetic resonance imaging (MRI), and region of interest analysis was carried out. Bayesian multivariate multilevel analyses found that the right lateral septum $(\operatorname{Pr}(b>0)=93 \%)$, left posterior cingulate cortex $(\operatorname{Pr}(b>0)=99 \%)$, and left anterior cingulate $(\operatorname{Pr}(b>0)=96 \%)$ showed higher FDG uptake in the jealousy condition compared to the control condition, while the right medial amygdala $(\operatorname{Pr}(b>0)$ $=85 \%$ ) showed lower FDG uptake. Plasma testosterone and cortisol concentrations were higher during the jealousy condition. During the jealousy condition, duration of time spent looking across at the pair mate next to a stranger male was associated with higher plasma cortisol concentrations. The lateral septum has been shown to be involved in mate-guarding and mating-induced aggression in monogamous rodents, while the cingulate cortex has been linked to territoriality. These neural and physiological changes may underpin the emotion of jealousy, which can act in a monogamous species to preserve the long-term integrity of the pair.

Keywords: monogamy, mate-guarding, mating-induced aggression, testosterone, lateral septum, cingulate cortex, vasopressin, cortisol 


\section{INTRODUCTION}

Shakespeare's "green-eyed monster" has been written about for centuries (Shakespeare, 1988), but the scientific study of jealousy is relatively young. Jealousy is an aspect of romantic relationships that works to maintain the relationship, but which can develop into intimate partner violence when unrestrained (Buss, 2002; Neal and Edwards, 2015). Jealousy may have given a fitness advantage to humans in our ancestral environment; current evidence shows that culture also plays a role (Harris, 2003). The emotion of jealousy is a form of social rejection that occurs when another individual (partner, parent, etc.) appears to devalue a relationship because of an outside third party (Leary, 2015). Because jealousy is an emotion that often occurs in the context of reproductive relationships, it is relevant to our understanding of the evolution and neurobiology of pair bonds.

The neural basis of jealousy in humans is not well understood in part because eliciting jealousy requires complex social interactions which may be difficult to create in a laboratory setting (Harmon-Jones et al., 2009). However, a large body of studies has suggested that social rejection of various types is mediated by the anterior cingulate cortex (Eisenberger, 2015). A recent functional magnetic resonance imaging (fMRI) study asked participants to imagine that an early stage romantic partner "did not prefer" them over a romantic rival. This jealousy condition provoked activation in the dorsal and ventral striatum (dopaminergic areas), as well as the cingulate cortex (Sun et al., 2016). Dopamine agonist therapy is also associated with delusional jealousy in Parkinson's patients (Poletti et al., 2012).

Investigating the neurobiology of jealousy in non-human primates that form pair bonds is an important step in understanding the evolution of monogamy. Male sexual "jealousy" was studied in the context of rhesus monkey consortships using positron emission tomography (PET) imaging (Rilling et al., 2004). Rhesus monkeys are not socially monogamous, but do form short-term consortships in which a male guards an estrus female (Manson, 1997; Palombit, 2014). When rhesus males viewed their consort next to a stranger male, they had increased $\left[{ }^{18} \mathrm{~F}\right]$-fluorodeoxyglucose (FDG) uptake in areas including the right amygdala and right superior temporal sulcus; plasma testosterone concentrations also increased (Rilling et al., 2004). Theoretically, a threat to a long-term reproductive and affiliative relationship might be even more salient than a threat to a short-term sexual consortship, because it is an attachment bond and there are more resources to lose (Ellis and Weinstein, 1986). Unlike rhesus monkeys, titi monkeys are socially monogamous and form long-term pair bonds, and thus might even have stronger "jealousy" reactions than rhesus monkeys (which only form consortships).

Social monogamy is displayed by a small minority of mammals, usually estimated at $3-5 \%$ of mammalian species (Kleiman, 1977; Lukas and Clutton-Brock, 2013; Diaz-Munoz and Bales, 2016; Tecot et al., 2016). In socially monogamous animals, the development of an adult attachment relationship or "pair bond" is associated with the onset of mate-guarding in both males and females (Mason, 1966; Winslow et al., 1993; McGuire and Getz, 1998; Fernandez-Duque et al., 2000; Bowler et al., 2002;
Getz et al., 2003; Fisher-Phelps et al., 2016; Tabbaa et al., 2016). This behavior helps maintain the relationship through aggression toward both same- and opposite-sex individuals. The pair bond is a construct encompassing a preference for the familiar partner, distress upon separation, and the ability of the pair mate to buffer stress (Mason and Mendoza, 1998). As such, it is very similar to a human romantic relationship (Hazan and Shaver, 1987; Sbarra and Hazan, 2008) and the pair mates might be expected to feel jealousy if a third party threatened that relationship. While the neurobiology of pair bonding has been best studied in a rodent model, the socially monogamous prairie vole (Microtus ochrogaster), the many potential differences between rodent and primate nervous systems make a primate model for pair bonding desirable as well (Phillips et al., 2014; Bales et al., 2017).

Titi monkeys (genus Callicebus) are small, arboreal primates which display social monogamy (including “jealousy” behavior) both in the field (Mason, 1966; Spence-Aizenberg et al., 2016; Van Belle et al., 2016) and in the laboratory (Mason, 1974; Mendoza and Mason, 1997; Carp et al., 2016). For example, in the wild, a male was observed placing himself in between his female pair mate and intruding male, and physically restraining his female pair mate to keep her from moving toward an “intruder" male (Mason, 1966). Wild titi monkeys of both sexes respond to conspecific playbacks by duetting and approaching the speaker, which may function as both territorial and mate defense (Caselli et al., 2015). Both males and females show strong arousal reactions toward outsiders, including tail-lashing and arched-back displays, and restraint of the pair mate to keep her/him away from the stranger, although males have stronger reactions than females (Cubiciotti and Mason, 1978; FernandezDuque et al., 2000). This jealousy reaction can be duplicated in a laboratory context either with live intruders (Fernandez-Duque et al., 2000) or by introduction of a mirror in which the pair sees their own reflections (Fisher-Phelps et al., 2016). Titi monkeys provide an ideal non-human primate to examine a challenge to the pair bond that could elicit a "jealousy" response. Ellis and Weinstein (Ellis and Weinstein, 1986) proposed that three conditions are necessary for eliciting jealousy: (1) an attachment relationship between two individuals, (2) valued resources that are part of the attachment bond, and (3) intrusion by a third individual that is perceived by one partner as wanting to become a receiver of resources. Titi monkeys fit these criteria since the (1) adult male and female form an attachment relationship with each other (unlike most other monkeys), and (2) titi monkeys naturally respond to "intruders" in the wild and captivity.

In addition to the potential neural changes associated with jealousy, we were also interested in the potential hormonal changes. In the rhesus monkey study, males who viewed their consort next to a stranger male had an increase in plasma testosterone concentrations (Rilling et al., 2004). While testosterone is the hormone most often associated with male jealousy or mate-guarding (Wingfield et al., 1990; Gray et al., 2017), there is also evidence for the role of vasopressin in aggression from both animals (Winslow et al., 1993; Ferris and Delville, 1994; Stribley and Carter, 1999; Gobrogge and Wang, 2016; Simmons et al., 2017) and humans (Marshall, 2013). Vasopressin and oxytocin are also involved in the neurobiology 
of pair bond formation (Numan and Young, 2016). A role for cortisol in jealousy is also plausible based on its responses to challenging social situations (Breuner and Hahn, 2003; Casto and Edwards, 2016; Beehner and Bergman, 2017; Mendoza, 2017).

In the current study, we examined potential changes in the neural and hormonal substrates in response to a challenge to the pair bond of male titi monkeys, using the previously mentioned rodent, rhesus monkey, and human studies as our guides for the outcome measures. We exposed our subjects to two conditions in which they viewed either (1) their female pair mate next to a stranger male (jealousy condition) or (2) a stranger female next to a stranger male (control condition). We expected to see increased $\left[{ }^{18} \mathrm{~F}\right]$-fluorodeoxyglucose (FDG) uptake in the lateral septum; this could be due to up-regulation of dopamine D1 receptors as has been observed in monogamous prairie voles who mate-guard (Aragona et al., 2006; Resendez et al., 2016) and titi monkeys who were recently paired (Hostetler et al., 2017). We also examined other areas implicated in jealousy in rodents (i.e., posterior cingulate cortex, medial amygdala, anterior hypothalamus), rhesus monkeys (i.e., insular cortex, superior temporal sulcus, Rilling et al., 2004), or humans (i.e., anterior cingulate, nucleus accumbens, caudate, putamen, ventral pallidum, Sun et al., 2016). While we do not specifically know the distribution of androgen receptors in titi monkeys, we did have a strong a priori prediction of increased plasma testosterone concentrations, because of testosterone's association with matingrelated aggression and competition (Gray et al., 2017; Wingfield, 2017). Similarly, we predicted increases in plasma hormone concentrations of cortisol, oxytocin, and vasopressin due to their association with social challenge (Mendoza, 2017).

\section{METHODS}

All experimental procedures were approved by the Animal Care and Use Committee of the University of California, Davis, and complied with National Institutes of Health ethical guidelines as set forth in the Guide for Lab Animal Care.

\section{Subjects}

Subjects were eight captive-born adult male titi monkeys (Callicebus cupreus) housed at the California National Primate Research Center (CNPRC) in Davis, CA. Subjects were a mean age of 7.7 years old (median 7.0, range 4.0-12.8), and were living with their female pair mates for a mean of 2.5 years (median 1.7, range 0.7-9.9). All subjects were parents of offspring living in the cage. Animals were fed twice daily $(0,830$ and $1,330 \mathrm{~h}) \mathrm{a}$ diet consisting of New World monkey chow, rice cereal, banana, apples, raisins, and baby carrots and water was available ad libitum. Further details of husbandry and training are available elsewhere (Tardif et al., 2006).

\section{Experimental Design and PET Scanning with FDG}

Functional imaging was used to examine how males viewing their pair mate in close proximity to a stranger male would differ in their regional cerebral glucose metabolism compared to viewing a stranger male next to a stranger female in adjacent cages. Subjects, pair mates and young offspring (less than 1 year old) were relocated to a metabolism room $48 \mathrm{~h}$ prior to their positron emission tomography (PET) scan. As in our previous PET studies (Bales et al., 2007; Hinde et al., 2016; Maninger et al., 2017), animals were relocated prior to the scan in order to reduce the possible effect of novel housing on brain metabolism. Animals were fasted $6-12 \mathrm{~h}$ prior to the scan, with water available throughout the pre-scan period. On the day of the scan, all of the animals were caught and removed from the cage. The subject was manually restrained while he received a bolus injection of $\left[{ }^{18} \mathrm{~F}\right]$ fluorodeoxyglucose (FDG, PETNET Solutions, Sacramento, CA, up to $2 \mathrm{mCi} / \mathrm{kg} \mathrm{IV}$, administered in a volume of $<2 \mathrm{ml}$ ) into the saphenous vein.

Following the FDG injection, the male was put back in his cage alone (since his pair mate and offspring were removed) for the $30 \mathrm{~min}$ conscious uptake period, where he had visual access to another cage that housed two animals separated by a wire mesh. In the jealousy condition, the two animals in the viewing cage were the subject's female pair mate and a stranger male (Figure 1). The stranger was a male who was unfamiliar to the subjects. Viewing a stranger male adjacent to his female pair mate was designed to challenge the pair bond and induce "jealousy" in the male subjects. In the control condition, there was a stranger female and a stranger male monkey (note that this was a different animal from the jealousy condition) in the viewing cage. Because titi monkeys are territorial animals when paired and can show aggression to opposite-sex strangers (Fernandez-Duque et al., 2013), the male and female in the viewing cage were separated by a wire mesh in order to prevent any physical aggression (and potential wounding) between the unfamiliar animals. This was important because there were no humans in the room during the FDG uptake period to stop any fights. During the control condition, the female pair mate was moved out of the testing room. The offspring were moved out of the testing room for both the control and jealousy conditions. A camera was placed at the side of the subject's cage and the male was filmed during the uptake period for $30 \mathrm{~min}$, while all of the humans left the room. Each of the eight males experienced both the jealousy and control conditions on separate days; there was a mean of 5.2 weeks (range 3-6.3) between testing days. The order of conditions was counterbalanced, such that four males experienced the jealousy condition before the control condition and four males experienced the control condition before the jealousy condition.

After the FDG uptake period, subjects were anesthetized with ketamine (25 mg/kg IM) and administered medetomidine $(0.05 \mathrm{mg} / \mathrm{kg} \mathrm{IM})$. After the subject was sedated, a $1 \mathrm{ml}$ blood sample was collected from the femoral vein and put into a heparin-containing tube, and a sample of cerebrospinal fluid (CSF) was collected and put on ice. In order to ensure that hormonal outcomes were not influenced by the considerable disturbances involved prior to collection of blood samples, care was taken to ensure that the time of day was comparable for a given subject tested in each condition. Testing started between 0,800 and $0,839 \mathrm{~h}$ for the first subject, and the second subject was tested approximately $1.5-2 \mathrm{~h}$ later. Cortisol concentrations for males tested in the first (earlier) group averaged $94.1 \pm$ $5.8 \mu \mathrm{g} / \mathrm{dl}$, while males tested in the later group averaged 55.7 


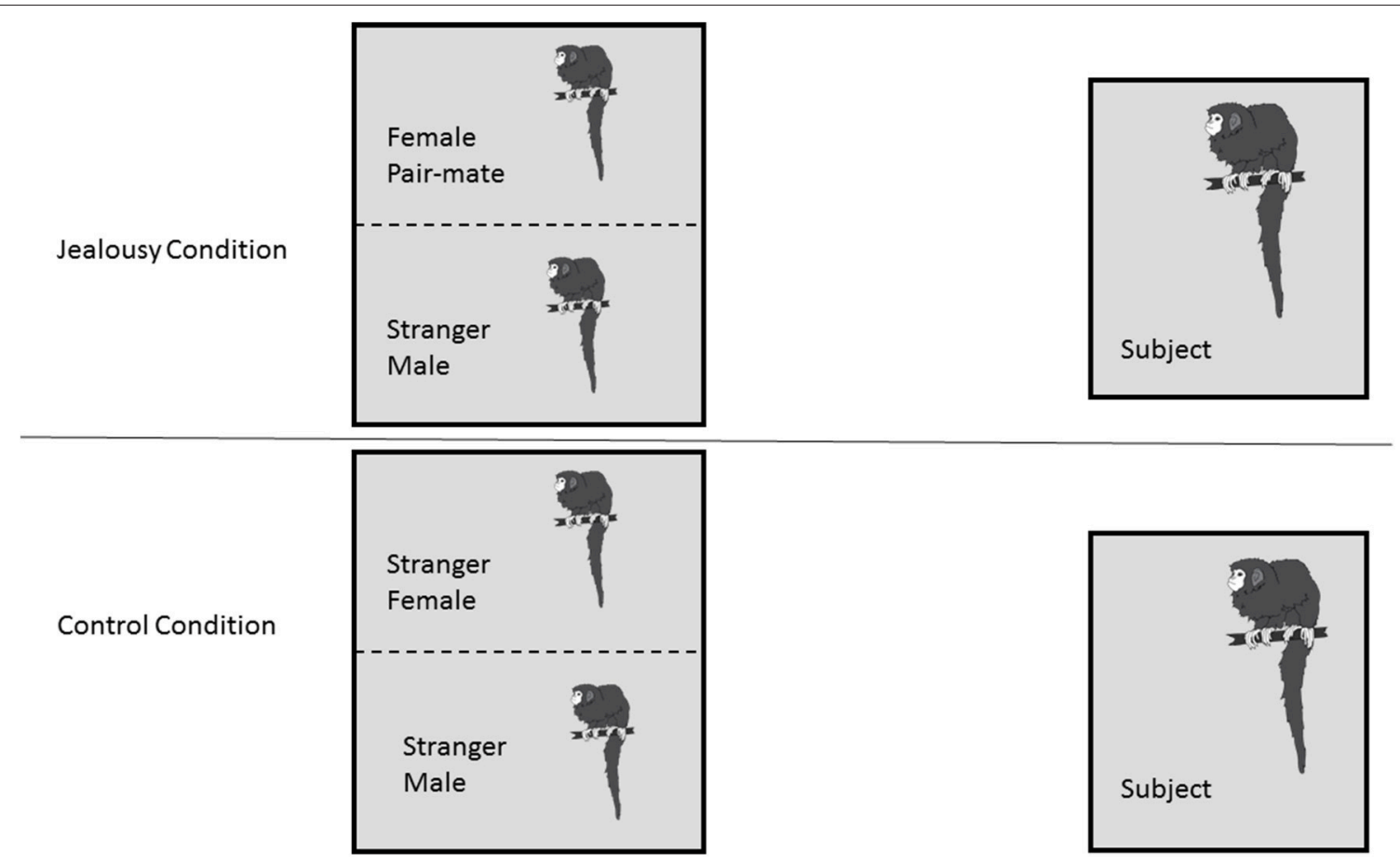

FIGURE 1 | Research Design. Subject males $(n=8)$ each underwent two conditions: a jealousy condition and a control condition. In the jealousy condition, they viewed their female pair mate next to a stranger male. In the control condition, males viewed two stranger animals, a stranger male and stranger female.

$\pm 7.2 \mu \mathrm{g} / \mathrm{dl}$. While time of day was correlated with cortisol concentrations $(r=-0.575)$, this effect of circadian rhythm was accounted for in the design of the study by carrying out both of an individual's scans (control and jealousy) in the same time grouping (early or late). For example, both of 32878's scans were carried out in the early group, and both of 31716 's scans were carried out in the late group. We also measured the duration of time between capture of the subject following FDG uptake until bloodand CSF sample collection (i.e., "disturbance time"). Disturbance time for blood samples was a mean of 5.22 min (median 4.80, range 1.72-16.15) after capture and sedation (raw data in Appendix 1). This disturbance time was not statistically correlated with plasma cortisol concentrations $(r=0.102)$. CSF samples were collected a mean of $9.50 \mathrm{~min}$ (median 9.88, range 5.75-13.13) after capture and sedation (raw data in Appendix 1; no statistical analysis on CSF data was carried out).

Following collection of blood and CSF samples, an endotracheal tube was placed and a catheter was placed in the saphenous vein in order to administer IV fluids (lactated ringers solution, $10 \mathrm{ml} / \mathrm{kg} / \mathrm{h}$ ). Atipamazole was used to reverse medetomidine, and anesthesia was maintained with isoflurane (1-2\%), while the male was positioned on the scanner bed feet first and the brain of the animal was positioned in the center of the scanner. PET imaging was performed on a microPET P4 scanner (Siemens Preclinical Solutions, Knoxville, TN). Image acquisition began a mean of 69.49 ( $\mathrm{SD} \pm 7.52$ ) minutes post-FDG administration, and static PET scans were acquired for $60 \mathrm{~min}$. Anesthesia was maintained throughout the scan. Animals were housed in metabolism cages for $24 \mathrm{~h}$ after scanning, at which time radiation was decayed to background levels and animals were returned to their home cages.

\section{MRI Scanning}

Structural magnetic resonance imaging (MRI) scans were conducted in a GE Signa LX 9.1 scanner (General Electric Corporation, Milwaukee, WI) with a $1.5 \mathrm{~T}$ field strength and a $3^{\prime \prime}$ surface coil. Each male was fasted 8-12 h before the procedure. At the start of the procedure, the male was sedated with ketamine (10 $\mathrm{mg} / \mathrm{kg} \mathrm{IM})$ and medazolam (0.1 mg/kg IM), and an endotracheal tube was placed. A catheter was also placed in the saphenous vein in order to administer fluids as necessary. Anesthesia was maintained with isoflurane (1-2\%) while the male was positioned in the MRI scanner. Each scan lasted approximately $20 \mathrm{~min}$ and consisted of a 3D SPGR pulse sequence in a coronal plane. Images of the entire brain were collected using the following parameters: echo time $\mathrm{TE}=7.9 \mathrm{~ms}$, repetition time $\mathrm{TR}=22.0 \mathrm{~ms}$, flip angle $=30.0^{\circ}$, field of view $=8 \mathrm{~cm}$, number of excitations $=3$, matrix $=256 \times 256$, and slice thickness $=1 \mathrm{~mm}$. As a precautionary measure, the male's EtCO2, oxygen saturation, heart rate and blood pressure were monitored throughout.

\section{PET and MRI Coregistration, Quantification of FDG Uptake}

We determined which regions of interest (ROIs) to quantify based on three groups of studies: rodent studies of aggression (lateral septum, medial amygdala, posterior cingulate cortex, and anterior hypothalamus), the Rilling rhesus monkey study 
of consortship (superior temporal cortex, insular cortex), and human studies of social pain and jealousy (anterior cingulate cortex, nucleus accumbens, ventral pallidum, caudate, and putamen) (Figure 2).

ROI structures were individually drawn on each subject's MRI image, for both left and right hemispheres, using landmarks as a guide, in Siemen's Inveon Research Workplace software (IRW, Siemens Healthcare, USA). ROIs were drawn prior to co-registrations with the PET image, so they were drawn blind with regard to PET image/FDG uptake and to experimental condition. The same ROIs were used for both the jealousy and control conditions. Static PET images were reconstructed with a 3DRP reconstruction protocol. MRI images were co-registered with PET scan images using the automatic rigid registration algorithm in IRW and checked visually for registration accuracy. Mean activity for the PET images were determined in IRW by applying ROIs defined on the MRI images to the PET images. Data are presented in proportions of whole brain activity, which was calculated by dividing the mean activity in the ROI (in units of microcuries per cubic centimeter) by mean activity of whole brain ROI.

\section{Behavioral Coding}

Males were filmed during the 30 min FDG uptake period. After all of the PET scans were completed, the videos were scored by a trained coder (T.S.) who was blind to experimental condition and validated against previous scoring done in the laboratory. Videos were scored on Behavior Tracker 1.5 (behaviortracker.com) for duration of the behaviors in the ethogram (see Table 1). Behaviors included lip smacking (an affiliative behavior), tail lashing (an arousal behavior), arching (an arousal behavior), as well as looking across at the stimulus cage, locomotion, chewing, drinking, and "off camera." Data analyses were performed on the total duration of each behavior (i.e., the absolute length of time the behavior was performed).

\section{Blood Sampling and Hormone Analysis}

Blood and CSF samples were collected after animals were sedated for the PET scan following the FDG uptake period, and placed on ice. Blood samples in heparin-containing tubes were centrifuged at 3,000 RPM for $15 \mathrm{~min}$ at $4^{\circ} \mathrm{C}$. Plasma was aliquoted, and plasma and CSF samples were stored at $-70^{\circ} \mathrm{C}$ until assay. CSF samples were assayed for oxytocin (OT) and vasopressin (AVP). Plasma samples were assayed for testosterone, cortisol, OT, and AVP. While the veterinarians collected as many CSF samples as possible, often they were unable to get a sample due to the small size of the animals (male subjects weighed a mean of $1.3 \mathrm{~kg}$, median 1.2 , range 1.1-1.6). Therefore, we present CSF values in Appendix 1, but did not have an adequate sample size to analyze them statistically.

AVP and OT concentrations were estimated in duplicate using commercial enzyme immunoassay kits (Enzo Life Sciences, Farmingdale, NY) previously validated for titi monkeys. Assay sensitivity was $2.34 \mathrm{pg} / \mathrm{ml}$ for AVP and $15.55 \mathrm{pg} / \mathrm{ml}$ for OT. Intra- and inter-assay coefficients of variation (CV) were 3.36 and $14.34 \%$ respectively for AVP, and 10.62 and $12.78 \%$, respectively for OT. Plasma cortisol and testosterone concentrations were estimated in duplicate using commercial radioimmunoassay kits (Siemens Healthcare, Malvern, PA). Prior to cortisol assay, plasma samples were diluted 1:4 in PBS gel buffer. Cortisol assay procedures were modified with the addition of 0.5 and $2.35 \mu \mathrm{g} / \mathrm{dl}$ concentrations of standards along with the provided range of 1.0$49 \mu \mathrm{g} / \mathrm{dl}$. Assay sensitivity was $0.261 \mu \mathrm{g} / \mathrm{dl}$. Intra- and inter-assay CV were 3.20 and $6.26 \%$, respectively. Prior to testosterone assay, plasma samples were diluted 1:2 in PBS gel buffer. Testosterone assay procedures were modified with the addition of 57 and 197.5 $\mathrm{ng} / \mathrm{dl}$ concentrations of standards along with the provided range of 24-1,667 ng/dl. Testosterone assay sensitivity was $4.58 \mathrm{ng} / \mathrm{dl}$. All samples were run in the same assay and intra-assay CV was $1.02 \%$.

\section{Data Analysis}

All models were fitted in a fully Bayesian multivariate multilevel framework for several reasons. First, due to our small sample size and large number of outcomes, multivariate models could not be estimated with least squares or maximum likelihood methods. Bayesian multivariate methods allowed for estimation of hypothesized regions of interest that included numerous correlated outcomes in one model. In addition, Bayesian multilevel methods fully account for uncertainty across levels of hierarchically structured data (McElreath, 2015), which was important due to our within-subjects design. Third, Bayesian methods allow for incorporating prior information into the model which improves precision of the parameter estimates (Gelman et al., 2008; Kruschke and Vanpaemel, 2015; see Supplementary Material for model details). Finally, parameter estimates have probabilistic interpretations, which allows for estimating the probability of a positive or negative experimental effect (Zucker et al., 1997; Lee, 2011).

In total, we fit five multivariate multilevel models. The first three models were based on hypothesized brain regions previously implicated as modulating jealousy-like behavior in different species: (1) mate-guarding in rodents; (2) jealousy or social pain in humans; and (3) bilateral regions from the rhesus monkey study. The next two multivariate multilevel models assessed hormonal and behavioral differences. The final models were exploratory, in that outcomes were determined from our results. These final models were not multilevel, but multivariate examining correlations between look duration and hormones as well as FDG uptake in ROIs (for the jealousy condition only). For these models, we standardized the predictors and response variables so that the estimates were on $r$ scale (correlation coefficient). All model based estimates are provided in Tables 2-6, whereas the raw means and standard deviations are provided with the model checks (Appendix 2).

Variance was partitioned into two components (Gelman and Hill, 2007): (1) the variance $\left(\sigma_{u}^{2}\right)$ between subjects (i.e., varying intercepts); and (2) the residual variance $\left(\sigma_{e}^{2}\right)$. As a measure of residual variance explained by subject, we computed intraclass correlation coefficients (ICC) (Quene and Van Den Bergh, 2004). Each multivariate model included one fixed effect, which provided a contrast from the control group. The parameter 

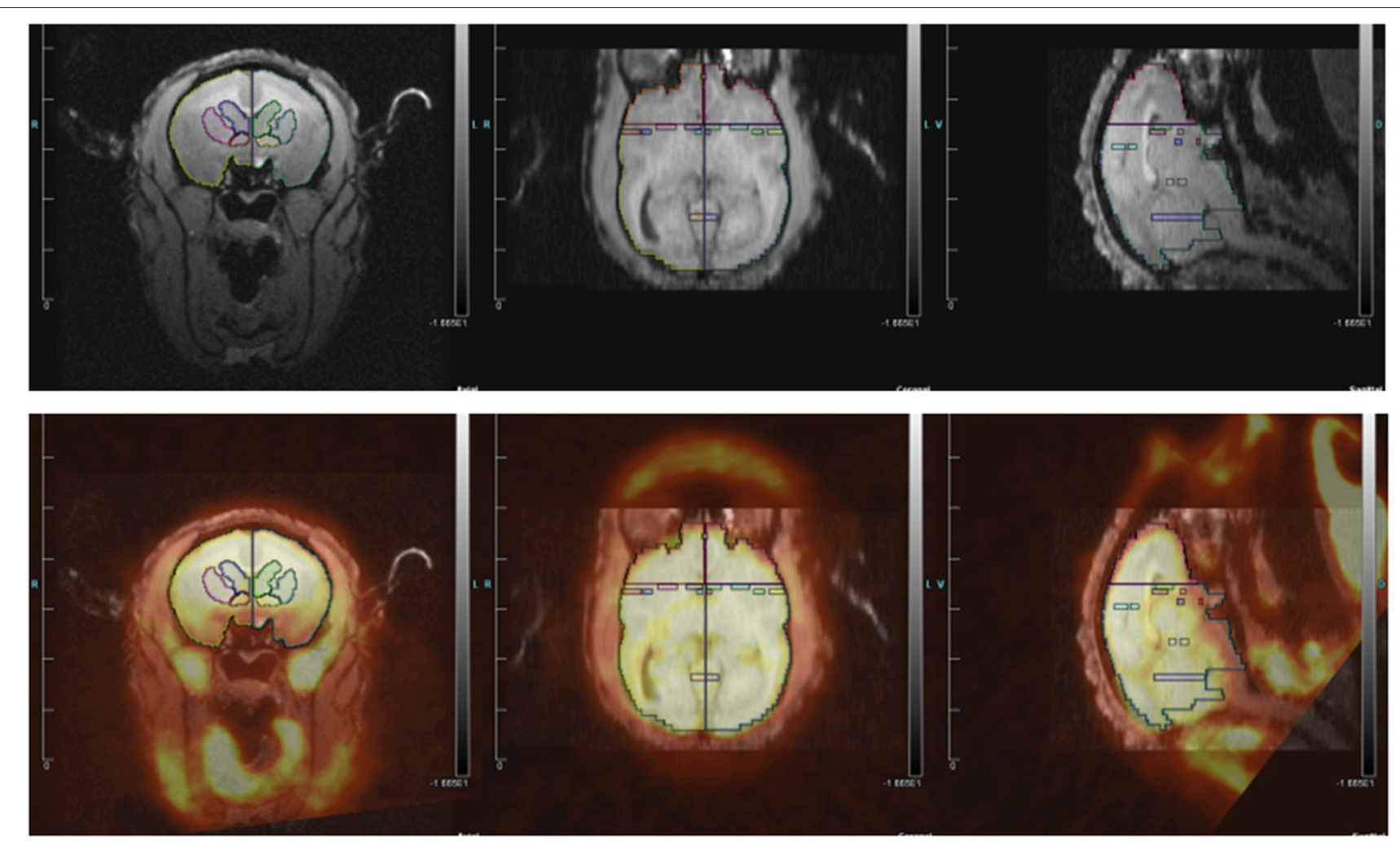

FIGURE 2 | (Top) MRI image with regions of interest. (Bottom) MRI image co-registered with PET for titi monkey in jealousy condition.

TABLE 1 | Ethogram.

\begin{tabular}{ll}
\hline Behavior* & Definition \\
\hline $\begin{array}{l}\text { Look Across } \\
\text { Lip smack }\end{array}$ & $\begin{array}{l}\text { Male's eyes gaze in the direction of the stimulus cage. } \\
\text { Male makes rapid lip movement accompanied by } \\
\text { smacking sound. } \\
\text { Arch }\end{array}$ \\
$\begin{array}{l}\text { Male raises dorsal surface of his back. May be } \\
\text { accompanied by piloerection. (This behavior along with } \\
\text { tail lash are "arousal behavior") }\end{array}$ \\
Tail lash & $\begin{array}{l}\text { Male whips his tail back and forth laterally. (This behavior } \\
\text { along with arch are "arousal behavior") }\end{array}$ \\
Locomotion & $\begin{array}{l}\text { Male moves at least one body length. } \\
\text { Male manipulates bandage (which covers his injection } \\
\text { Chew/pick bandage } \\
\text { site) with his mouth or hands. } \\
\text { Male drinks water. Begins when mouth touches lixit and } \\
\text { ends when drinking terminates. } \\
\text { Male is out of view of the camera. }\end{array}$ \\
\hline
\end{tabular}

${ }^{\star}$ All behaviors were analyzed as total durations.

estimates were summarized with $95 \%$ credibility intervals $(\mathrm{CrI})$ that, by definition, have a $95 \%$ probability of containing the true parameter (Morey et al., 2015). Bayesian methods provide probabilistic estimates that allow for explicit statements about likely values for the true treatment effect. We thus computed posterior probabilities of a positive or negative effect $(\operatorname{Pr}(b>$ $0)$ and $\operatorname{Pr}(b<0))($ Gelman, 2013; Greenland and Poole, 2013).
This is not possible with classical methods, since parameters are assumed to be fixed point estimates (probability distributions cannot exist). Posterior probabilities $>80 \%$ are reported in the results section, but all estimates are provided in tables. The $80 \%$ figure was chosen merely as a convenient figure in order to simplify the reporting of the results. Finally, an effect size parameter $\left(\delta_{T}\right)$ was obtained from dividing the estimate (b) by the square root of the variance components summed $\left(\sqrt{\sigma_{u}^{2}+\sigma_{e}^{2}}\right)$ (Hedges, 2007). Interpretation of $\left(\delta_{T}\right)$ follows Cohen's $d$ (Cohen, 2009; small $=0.2$, medium $=0.5$, large $=$ $0.8)$.

The jealousy condition for one male was not usable for technical reasons, thus the final sample size was 8 control scans and 7 jealousy scans, for 8 total subjects. Due to the complexity of the multivariate multilevel models, we examined fit with posterior predictive checks and posterior predictive $p$-values (Gelman et al., 1996; de la Horra and Rodriguea-Bernal, 1999). Here, the fitted model was used to simulate data, from which a properly specified model will provide replications that look like the observed data and non-extreme $p$-values $(0.95>p$ value $>0.05)$. For most models, the posterior predictive $p$-values indicated that model fit was adequate (Appendix 2).

All computation was done in $\mathrm{R}$ (Team, 2016). The package brms (Buerkner, 2015), a front end to the probabilistic programming language Stan (Stan_Development_Team, 2015), was used to fit all regression models (all $\mathrm{R}$ script and data are available upon request). 
TABLE 2 | Multivariate multilevel model estimates for regions of interest implicated by rodent studies as modulating mate-guarding behavior.

\begin{tabular}{|c|c|c|c|c|c|c|c|}
\hline ROI & & $b$ & $\begin{array}{l}\text { Post. } \\
\text { SD }\end{array}$ & $95 \% \mathrm{Crl}$ & $\delta_{T}$ & $\begin{array}{l}\operatorname{Pr} \\
(b>0)\end{array}$ & $\begin{array}{l}\mathrm{Pr} \\
(b<0)\end{array}$ \\
\hline \multirow[t]{2}{*}{ LS-L } & Intercept & 0.96 & 0.03 & $0.87,1.02$ & - & - & - \\
\hline & Jealousy & -0.02 & 0.04 & $-0.08,0.06$ & -0.18 & $31 \%$ & $69 \%$ \\
\hline \multirow[t]{2}{*}{ LS-R } & Intercept & 0.91 & 0.03 & $0.85,0.97$ & - & - & - \\
\hline & Jealousy & 0.04 & 0.03 & $-0.02,0.10$ & 0.55 & $93 \%$ & $7 \%$ \\
\hline \multirow[t]{2}{*}{$\mathrm{AH}-\mathrm{L}$} & Intercept & 0.67 & 0.03 & $0.61,0.74$ & - & - & - \\
\hline & Jealousy & 0.01 & 0.04 & $-0.07,0.10$ & 0.14 & $63 \%$ & $37 \%$ \\
\hline \multirow[t]{2}{*}{$\mathrm{AH}-\mathrm{R}$} & Intercept & 0.69 & 0.03 & $0.62,0.76$ & - & - & - \\
\hline & Jealousy & -0.04 & 0.04 & $-0.12,0.05$ & -0.35 & $20 \%$ & $80 \%$ \\
\hline \multirow[t]{2}{*}{ PCC-L } & Intercept & 1.07 & 0.01 & $1.01,1.09$ & - & - & - \\
\hline & Jealousy & 0.04 & 0.02 & $0.01,0.07$ & 1.02 & $98 \%$ & $2 \%$ \\
\hline \multirow[t]{2}{*}{ PCC-R } & Intercept & 1.09 & 0.02 & $1.05,1.14$ & - & - & - \\
\hline & Jealousy & 0.01 & 0.03 & $-0.05,0.06$ & 0.05 & $55 \%$ & $45 \%$ \\
\hline \multirow[t]{2}{*}{ MeA-L } & Intercept & 0.70 & 0.03 & $0.64,0.75$ & - & - & - \\
\hline & Jealousy & -0.01 & 0.03 & $-0.07,0.06$ & -0.04 & $44 \%$ & $56 \%$ \\
\hline \multirow[t]{2}{*}{ MeA-R } & Intercept & 0.70 & 0.03 & $0.64,0.76$ & - & - & - \\
\hline & Jealousy & -0.03 & 0.03 & $-0.10,0.03$ & -0.40 & $16 \%$ & $84 \%$ \\
\hline
\end{tabular}

Intercept is the model estimate for the control condition. Jealousy is the difference from the control condition - the jealousy effect. Post. SD is the posterior standard deviation of the estimate. These estimates were all obtained from the same model. Interpretation of $\left(\delta_{T}\right)$ follows Cohen's $d$ (small $=0.2$, medium $=0.5$, large $=0.8$ ).

\section{A Note on Interpretation of Results}

The use of Bayesian statistics remains relatively uncommon. This may be seen as a limitation when comparing our results to the extant literature. Indeed, our use of Bayesian methods has different goals than typically pursued: we did not focus on rejecting a null hypothesis. Instead, our analysis sought to quantify the most probable values for the "true" effect of jealousy on regional cerebral glucose metabolism, hormones and behavior in titi monkeys. This is not possible with classical methods (e.g., ANOVA) in which evidential quantities (e.g., $p$-values) are in reference to counterfactual sampling procedures. When inferring from our results, the posterior probabilities can be directly interpreted as probabilities (how probability is used in everyday language). The present approach does not include thresholds (i.e., cut-offs, but of course a probability of $99 \%$ provides stronger evidence than $85 \%$, assuming equal prior odds). A meaningful probability can be determined in light of theory, past research, the quality of this study (including limitations), and the reported results (Harrell and Shih, 2001; Gelman, 2013; Greenland and Poole, 2013; Gelman et al., 2014; Kruschke, 2014).

\section{RESULTS \\ FDG Uptake}

Our first multivariate multilevel model simultaneously estimated areas implicated by rodent studies as modulating mate-guarding behavior: the lateral septum (LS), anterior hypothalamus (AH), posterior cingulate cortex (PCC), and medial amygdala (MeA). The probability of a positive effect of jealousy condition on FDG uptake in the right LS was $93 \%(b=0.04, C r I=[-0.02-0.10]$,
TABLE 3 | Multivariate multilevel model estimates for regions of interest shown to be associated with jealousy and social pain in humans.

\begin{tabular}{|c|c|c|c|c|c|c|c|}
\hline ROI & & $b$ & $\begin{array}{l}\text { Post. } \\
\text { SD }\end{array}$ & $95 \% \mathrm{Crl}$ & $\delta_{T}$ & $\begin{array}{l}\operatorname{Pr} \\
(b>0)\end{array}$ & $\begin{array}{l}\mathrm{Pr} \\
(b<0)\end{array}$ \\
\hline \multirow[t]{2}{*}{ AC-L } & Intercept & 1.06 & 0.02 & $1.04,1.10$ & - & - & - \\
\hline & Jealousy & 0.05 & 0.03 & $-0.01,0.10$ & 0.79 & $96 \%$ & $4 \%$ \\
\hline \multirow[t]{2}{*}{ AC-R } & Intercept & 1.08 & 0.02 & $1.04,1.12$ & - & - & - \\
\hline & Jealousy & 0.01 & 0.02 & $-0.04,0.05$ & 0.09 & $60 \%$ & $40 \%$ \\
\hline \multirow[t]{2}{*}{ Ca-L } & Intercept & 1.13 & 0.03 & $1.07,1.18$ & - & - & - \\
\hline & Jealousy & -0.01 & 0.03 & $-0.08,0.06$ & -0.14 & $36 \%$ & $64 \%$ \\
\hline \multirow[t]{2}{*}{$\mathrm{Ca}-\mathrm{R}$} & Intercept & 1.06 & 0.03 & $0.99,1.13$ & - & - & - \\
\hline & Jealousy & 0.04 & 0.03 & $-0.03,0.09$ & 0.41 & $90 \%$ & $10 \%$ \\
\hline \multirow[t]{2}{*}{ P-L } & Intercept & 1.18 & 0.02 & $1.14,1.23$ & - & - & - \\
\hline & Jealousy & 0.02 & 0.02 & $-0.03,0.06$ & 0.26 & $79 \%$ & $21 \%$ \\
\hline \multirow[t]{2}{*}{ P-R } & Intercept & 1.15 & 0.04 & $1.06,1.24$ & - & - & - \\
\hline & Jealousy & -0.02 & 0.05 & $-0.12,0.08$ & -0.19 & $31 \%$ & $69 \%$ \\
\hline \multirow[t]{2}{*}{ NAcc-L } & Intercept & 0.96 & 0.05 & $0.86,1.06$ & - & - & - \\
\hline & Jealousy & 0.02 & 0.06 & $-0.10,0.12$ & 0.27 & $76 \%$ & $24 \%$ \\
\hline \multirow[t]{2}{*}{ NAcc-R } & Intercept & 0.89 & 0.03 & $0.83,0.96$ & - & - & - \\
\hline & Jealousy & 0.02 & 0.04 & $-0.05,0.09$ & 0.11 & $62 \%$ & $38 \%$ \\
\hline \multirow[t]{2}{*}{ VP-L } & Intercept & 0.83 & 0.04 & $0.76,0.90$ & - & - & - \\
\hline & Jealousy & 0.05 & 0.04 & $-0.04,0.13$ & 0.38 & $88 \%$ & $12 \%$ \\
\hline \multirow[t]{2}{*}{ VP-R } & Intercept & 0.79 & 0.03 & $0.72,0.85$ & - & - & - \\
\hline & Jealousy & 0.03 & 0.03 & $-0.03,0.10$ & 0.45 & $86 \%$ & $14 \%$ \\
\hline
\end{tabular}

Intercept is the model estimate for the control condition. Jealousy is the difference from the control condition - the jealousy effect. Post. SD is the posterior standard deviation of the estimate. These estimates were all obtained from the same model. Interpretation of $\left(\delta_{T}\right)$ follows Cohen's $d$ (small $=0.2$, medium $=0.5$, large $=0.8$ ).

$\delta_{T}=0.55$; Figure 3A) and, similarly, 99\% in the left PCC ( $b$ $=0.04, \mathrm{CrI}=[0.01-0.07], \delta_{T}=1.02$; Figure 3B), while there was some evidence for reduced uptake in the right $\mathrm{MeA}(\operatorname{Pr}(b$ $<0)=85 \%, b=-0.03, C r I=[-0.10-0.03], \delta_{T}=-0.40$; Figure 3A). The posterior probabilities for the other comparisons were below $80 \%$ and are reported in Table 2 . Notably, the amount of variation explained by subject across outcomes ranged from $9 \%$ (left AH: ICC $=0.09, C r I=[0.00-0.44]$ ) to $42 \%$ (right LS: $\mathrm{ICC}=0.42, \mathrm{CrI}=[0.004-0.87])$.

Our second multivariate multilevel model examined several cortical areas that were shown to be associated with jealousy or social pain in human studies [anterior cingulate cortex (AC), caudate $(\mathrm{Ca})$, putamen $(\mathrm{P})$, nucleus accumbens (NAcc), and ventral pallidum (VP)]. The probability of a positive effect of jealousy condition on FDG uptake in the left AC was 96\% $\left.\left(b=0.05, C r I=[-0.01-0.10], \delta_{T}=0.79\right)\right]$, while there was some evidence for reduced uptake in the right $\mathrm{Ca}(\operatorname{Pr}(b>0)$ $\left.=90 \%, b=0.04, C r I=[-0.03-0.10], \delta_{T}=0.41\right)$, right $\mathrm{VP}$ $\left(\operatorname{Pr}(b>0)=86 \%, b=0.05, C r I=[-0.03-0.13], \delta_{T}=0.38\right)$, and the left VP $(\operatorname{Pr}(b>0)=88 \%, b=0.04, C r I=[-0.03-$ 0.13], $\left.\delta_{T}=0.38\right)$. According to the posterior predictive checks, model fit was adequate. The other comparisons are provided in Table 3. The amount of residual variation explained by subject across outcomes ranged from 13\% (left VP: ICC $=0.13, \mathrm{CrI}$ $=[0.00-0.56])$ to $53 \%$ (right Ca: ICC $=0.53, \mathrm{CrI}=[0.02-$ $0.89])$. 
TABLE 4 | Multivariate multilevel model estimates for regions from the rhesus monkey study.

\begin{tabular}{llcccccl}
\hline ROI & & $\boldsymbol{b}$ & $\begin{array}{c}\text { Post. } \\
\text { SD }\end{array}$ & $\mathbf{9 5 \%} \mathbf{C r}$ & $\boldsymbol{\delta}_{\boldsymbol{T}}$ & $\begin{array}{l}\mathbf{P r} \\
\mathbf{( b}>\mathbf{0})\end{array}$ & $\begin{array}{l}\mathbf{P r} \\
(\boldsymbol{b}<\mathbf{0})\end{array}$ \\
\hline IC-L & Intercept & 1.09 & 0.03 & $1.03,1.14$ & - & - & - \\
& Jealousy & -0.01 & 0.03 & $-0.07,0.04$ & -0.16 & $27 \%$ & $73 \%$ \\
IC-R & Intercept & 1.07 & 0.03 & $1.02,1.13$ & - & - & - \\
& Jealousy & 0.01 & 0.03 & $-0.05,0.06$ & 0.09 & $63 \%$ & $37 \%$ \\
ST-L & Intercept & 1.01 & 0.05 & $0.91,1.12$ & - & - & - \\
& Jealousy & 0.01 & 0.04 & $-0.07,0.09$ & 0.07 & $62 \%$ & $38 \%$ \\
ST-R & Intercept & 1.04 & 0.11 & $0.84,1.25$ & - & - & - \\
& Jealousy & 0.02 & 0.07 & $-0.11,0.15$ & 0.06 & $62 \%$ & $38 \%$ \\
\hline
\end{tabular}

Intercept is the model estimate for the control condition. Jealousy is the difference from the control condition - the jealousy effect. Post. SD is the posterior standard deviation of the estimate. These estimates were all obtained from the same model. Interpretation of $\left(\delta_{T}\right)$ follows Cohen's $d$ (small $=0.2$, medium $=0.5$, large $=0.8$ ).

TABLE 5 | Multivariate multilevel model estimates for plasma hormone concentrations.

\begin{tabular}{|c|c|c|c|c|c|c|c|}
\hline ROI & & $b$ & $\begin{array}{l}\text { Post. } \\
\text { SD }\end{array}$ & $95 \% \mathrm{Crl}$ & $\delta_{T}$ & $\begin{array}{l}\operatorname{Pr} \\
(b>0)\end{array}$ & $\begin{array}{l}\operatorname{Pr} \\
(b<0)\end{array}$ \\
\hline \multirow[t]{2}{*}{ OT } & Intercept & 509.65 & 67.16 & $378.36,647.11$ & - & - & - \\
\hline & Jealousy & 23.01 & 68.26 & $-120.78,155.07$ & 0.13 & $65 \%$ & $35 \%$ \\
\hline \multirow[t]{2}{*}{ AVP } & Intercept & 263.17 & 25.60 & $212.61,316.62$ & - & - & - \\
\hline & Jealousy & 17.72 & 29.51 & $-42.55,75.83$ & 0.25 & $74 \%$ & $26 \%$ \\
\hline \multirow[t]{2}{*}{ Cortisol } & Intercept & 75.67 & 9.32 & $56.76,93.98$ & - & - & - \\
\hline & Jealousy & 10.13 & 7.35 & $-4.83,24.48$ & 0.41 & $92 \%$ & $8 \%$ \\
\hline \multirow[t]{2}{*}{ Testosterone } & Intercept & 410.88 & 160.66 & $129.45,723.02$ & - & - & - \\
\hline & Jealousy & 190.17 & 129.97 & $-85.38,440.42$ & 0.48 & $93 \%$ & $7 \%$ \\
\hline
\end{tabular}

Intercept is the model estimate for the control condition. Jealousy is the difference from the control condition - the jealousy effect. Post. SD is the posterior standard deviation of the estimate. These estimates were all obtained from the same model. Interpretation of $\left(\delta_{T}\right)$ follows Cohen's $d$ (small $=0.2$, medium $=0.5$, large $=0.8$ ).

The third multivariate multilevel model estimated bilateral ROIs from the rhesus monkey study [insular cortex (IC) and superior temporal sulcus (ST)]. This model produced negligible probabilities for an effect of jealousy, and residual variation attributed to subjects was minimal (all instances $<5 \%$ ). Importantly, posterior predictive check indicated a misfit between the observed and the model implied standard deviations (Appendix 2; Table 4). Assuming equal variances was problematic, but unfortunately a heteroskedastic model could not be fit (due to an already complex model).

\section{Hormones}

Our multivariate multilevel model estimated plasma hormone concentrations of oxytocin (OT), vasopressin (AVP), cortisol, and testosterone in the jealousy condition compared to the control condition. There was a positive effect $(\operatorname{Pr}(b>0)=93 \%)$ of jealousy condition on plasma testosterone ( $b=190.17, \mathrm{CrI}$ $\left.=[-85.38-440.42], \delta_{T}=0.48\right)$ as well as similar evidence $(\operatorname{Pr}(b>0)=92 \%)$ for a positive effect on plasma cortisol $\left(b=10.13, C r I=[-4.83-24.48], \delta_{T}=0.40\right)$. Posterior
TABLE 6 | Multivariate multilevel model estimates for behaviors (duration).

\begin{tabular}{|c|c|c|c|c|c|c|c|}
\hline Behavior & & $b$ & $\begin{array}{l}\text { Post. } \\
\text { SD }\end{array}$ & $95 \% \mathrm{Crl}$ & $\delta_{T}$ & $\begin{array}{l}\operatorname{Pr} \\
(b>0)\end{array}$ & $\begin{array}{l}\operatorname{Pr} \\
(b<0)\end{array}$ \\
\hline \multirow[t]{2}{*}{ Tail lash } & Intercept & 1.41 & 1.81 & $-2.20,4.90$ & - & - & - \\
\hline & Jealousy & 0.14 & 0.18 & $-0.23,0.51$ & 0.03 & $75 \%$ & $15 \%$ \\
\hline \multirow[t]{2}{*}{ Arch } & Intercept & 15.45 & 8.07 & $-0.58,31.15$ & - & - & - \\
\hline & Jealousy & -10.51 & 9.88 & $-29.60,9.75$ & -0.49 & $13 \%$ & $87 \%$ \\
\hline \multirow[t]{2}{*}{ Look across } & Intercept & 145.72 & 45.57 & $55.98,239.23$ & - & - & - \\
\hline & Jealousy & 6.28 & 54.11 & $-101.40,116.81$ & 0.05 & $55 \%$ & $45 \%$ \\
\hline \multirow[t]{2}{*}{ Lip smack } & Intercept & 3.01 & 5.38 & $-7.66,13.50$ & - & - & - \\
\hline & Jealousy & 7.60 & 5.90 & $-4.19,19.75$ & 0.55 & $90 \%$ & $10 \%$ \\
\hline \multirow[t]{2}{*}{ Locomotion } & Intercept & 261.85 & 87.39 & $78.18,437.65$ & - & - & - \\
\hline & Jealousy & -14.51 & 104.07 & $-222.03,195.26$ & -0.06 & $44 \%$ & $56 \%$ \\
\hline \multirow[t]{2}{*}{ Chew } & Intercept & 123.73 & 42.85 & $40.55,280.42$ & - & - & - \\
\hline & Jealousy & -19.81 & 59.22 & $-139.99,99.02$ & -0.17 & $37 \%$ & $63 \%$ \\
\hline
\end{tabular}

Intercept is the model estimate for the control condition. Jealousy is the difference from the control condition - the jealousy effect. Post. SD is the posterior standard deviation of the estimate. These estimates were all obtained from the same model. Interpretation of $\left(\delta_{T}\right)$ follows Cohen's $d$ (small $=0.2$, medium $=0.5$, large $=0.8$ ).

predictive checks indicated that the model adequately described the observed data. The amount of residual variation explained by subjects ranged from 17\% (AVP: ICC $=0.17, \mathrm{CrI}=$ $[0.00-0.67])$ to $63 \%$ (cortisol: $\mathrm{ICC}=0.62, \mathrm{CrI}=[0.03-0.92]$ ). Plasma OT and AVP concentrations had lower probabilities (65 and 74\%, respectively) for differences between conditions (Table 5; also presented are model estimates and confidence intervals).

\section{Behavior}

The multivariate multilevel model estimated differences in total durations of behavior between the control and jealousy conditions (for ethogram see Table 1). Due to excessive zeroes, drinking and time off camera were not analyzed. There was some evidence for a positive effect $(\operatorname{Pr}(b>0)=90 \%)$ of jealousy condition on lip smacking duration $\left(b=7.60, C r I=[-4.19-19.75], \delta_{T}=0.55\right)$. The residual variance explained by subject ranged from $14 \%$ (chewing: ICC $=0.14, \mathrm{CrI}=[0-0.59]$ ) to $99 \%$ (tail lashing: ICC $=0.99, C r I=[0.97-1.0])$. All estimates are reported in Table 6.

\section{Correlations: Jealousy Condition}

Durations of behaviors were standardized prior to analysis, resulting in correlations $(r)$. Look duration via a single-level multivariate model was positively correlated with cortisol $(b=$ 0.63, $C r I=[-0.07-0.98], \operatorname{Pr}(b>0)=97 \%)$. The correlation with testosterone was also positive, but the interval was very wide ( $b=$ $0.31, C r I=[-0.67-0.94], \operatorname{Pr}(b>0)=78 \%)$. Using a single-level multivariate model to investigate associations between behavior and brain region of interest, we found that look across duration had a probability of a positive correlation on FDG uptake in the right LS of $92 \%$ ( $b=0.53, C r I=[-0.32-0.97]$; Figure $4 \mathrm{~A})$. There were substantial negative correlations with look duration in the left PCC $(b=-0.46, C r I=[-0.97-0.35], \operatorname{Pr}(b<0)=$ 
A

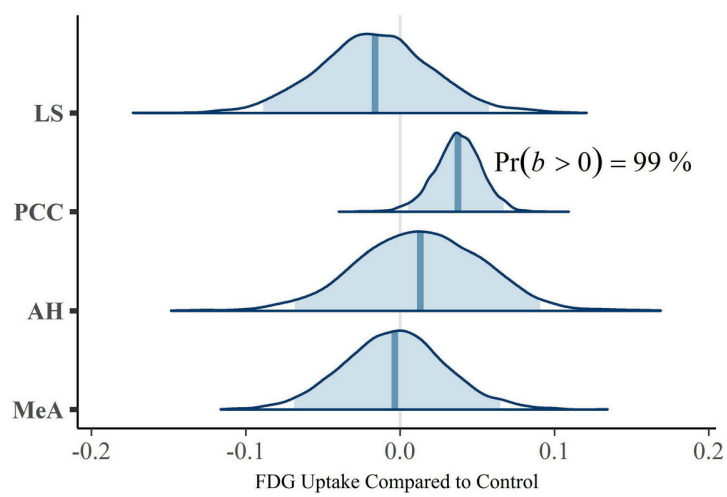

B

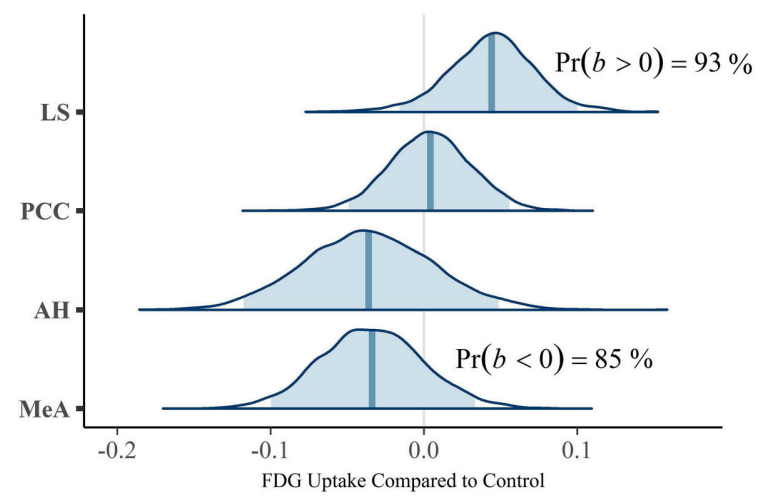

FIGURE 3 | Posterior distributions from the multivariate multilevel mate guarding model. The density plots are the parameter estimates (contrasts from the control group). The shaded blue regions are the $95 \%$ credible regions, while the dark blue lines are the point estimates. (A) Left ROls. (B) Right ROls.
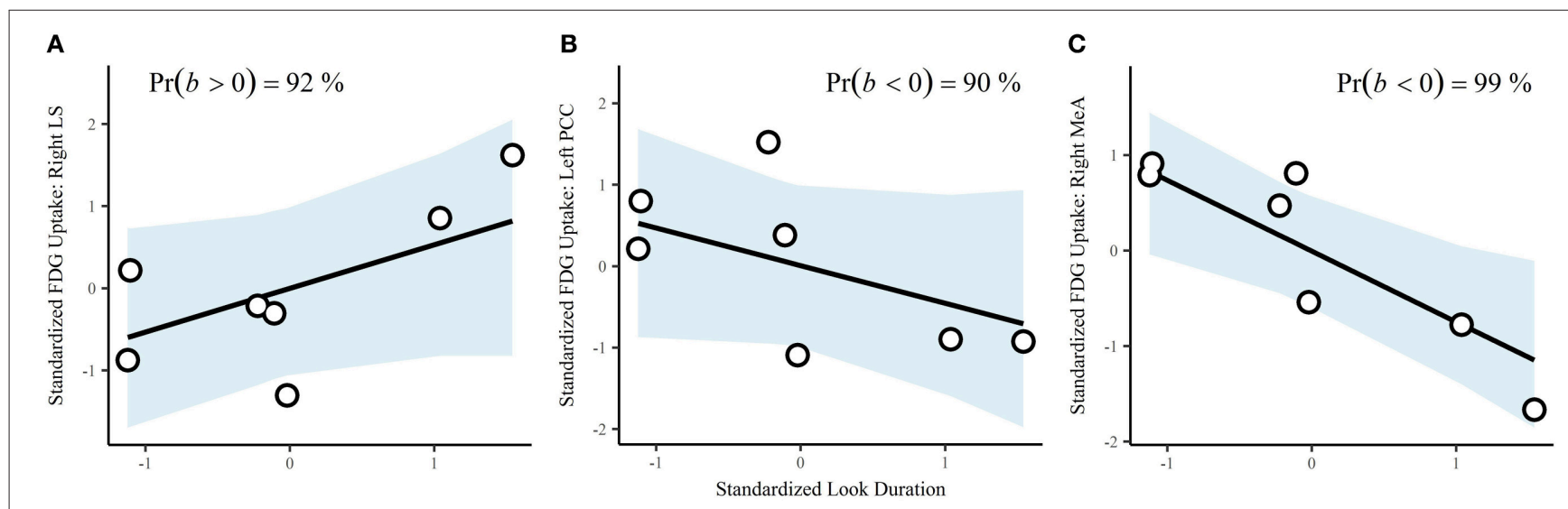

FIGURE 4 | Correlations between look duration and ROls: (A), right lateral septum; (B), left posterior cingulate cortex, and (C), right medial amygdala. Points are the observed data. The blue shaded areas are the fitted 95\% credible regions for the correlations.

90\%; Figure 4B) and the right $\mathrm{MeA}(b=-0.74, \mathrm{CrI}=[-0.99$ to $-0.22], \operatorname{Pr}(b<0)=99 \%$; Figure 4C).

The probability of a negative correlation between plasma testosterone and FDG uptake in the right MeA was $96 \%(b=$ $-0.57, C r I=[-0.97-0.07]), 48 \%$ for the right LS $(b=-0.03, C r I$ $=[-0.84-0.80])$, and $79 \%$ for the left PCC $(b=-0.57, \mathrm{CrI}=$ $[-0.93,0.60])$. There were negative correlations between cortisol concentrations and FDG uptake in the left PCC $(b=-0.19, \mathrm{CrI}$ $=[-0.91,0.70], \operatorname{Pr}(b<0)=72 \%)$, and right $\mathrm{MeA}(b=-0.54$, $C r I=[-0.97,0.22], \operatorname{Pr}(b<0)=93 \%)$. There was a positive correlation between cortisol concentrations and FDG uptake in the right LS $(b=0.31, C r I=[-0.66,0.94], \operatorname{Pr}(b>0)=81 \%)$, but the interval was very wide.

\section{DISCUSSION}

After seeing his female pair mate next to a stranger male, male titi monkeys showed increased FDG uptake in the right lateral septum (LS), left posterior cingulate cortex (PCC) and left anterior cingulate (AC), and decreased uptake in the right medial amygdala (MeA) compared to the control condition. Our subjects also had higher plasma testosterone and cortisol concentrations and spent more time lip smacking in the jealousy condition compared to the control condition. In the jealousy condition, the amount of time looking at the pair mate next to a stranger male was associated with higher plasma cortisol concentrations. These neural and physiological changes may underpin the emotion of jealousy, which can act in a monogamous species to preserve the long-term integrity of the pair.

We now have multiple lines of evidence suggesting that the lateral septum plays a role in both pair bond formation and pair bond maintenance in titi monkeys. The lateral septum is innervated by vasopressin fibers in many mammalian species, including a number of primate species (Ragen and Bales, 2013). In titi monkeys it contains oxytocin receptors but not vasopressin receptors (Freeman et al., 2014), suggesting that any actions of vasopressin in that area are mediated through oxytocin receptors (Barberis and Tribollet, 1996). In addition, it receives 
dopaminergic input from the ventral tegmental area (Sheehan et al., 2004). In our initial cross-sectional study comparing pair bonded males to males that were housed alone, FDG uptake in the lateral septum was statistically different between the two groups, with a difference of 9\% (Bales et al., 2007). Dopamine D1 receptor binding in the lateral septum of male titi monkeys is also statistically significantly up-regulated 4-9 weeks following pair bonding (Hostetler et al., 2017). In socially monogamous prairie voles, up-regulation of D1 receptors is associated with the onset of mate-guarding, although in that case the sensitive neural area is the nucleus accumbens (Aragona et al., 2006). The lateral septum also plays an important role in social memory (Everts and Koolhaas, 1999) and in the preference formation aspects of pair bonding (Liu et al., 2001). The lateral septum also modulates stress in many species, via an oxytocinergic mechanism (Singewald et al., 2011; Guzman et al., 2013), and stress can modulate the process of social bonding (DeVries et al., 1996). In this study, the medium-large effect size that we found suggests not just a long-term change in dopamine neurochemistry (Hostetler et al., 2017), but also a strong involvement in acute responses to a threat to the pair bond.

In the present study we also found higher FDG uptake in the left posterior cingulate cortex in the jealousy condition, as well as evidence for a positive effect in the left anterior cingulate. In semi-free-ranging prairie voles, higher vasopressin receptor binding in the posterior cingulate was associated with higher fidelity to the partner (Ophir et al., 2008), which theoretically could be related to a stronger pair bond or more time spent in proximity mate-guarding. The fact that we also found evidence for higher FDG uptake in the anterior portion of the cingulate (and that the effect sizes for both posterior and anterior were large and remarkably similar in magnitude) suggests that our "jealousy" condition affects the left cingulate cortex as a whole, and is not just confined to the posterior cingulate. There are well-studied associations between anterior cingulate cortex and socially painful situations (Eisenberger, 2015), which fits with the view of jealousy as social rejection.

Our study found lateralized effects of the jealousy condition on regional cerebral glucose metabolism, such that male titi monkeys showed increased FDG uptake in the right lateral septum (LS), left posterior cingulate cortex (PCC) and left anterior cingulate (AC), and decreased FDG uptake in the right medial amygdala (MeA) in the jealousy condition compared to the control. Lateralized effects have also been found in human studies of jealousy or other forms of social exclusion. In a human study on jealousy using electroencephalogram (EEG) to measure electrical activity of the brain, jealousy evoked by a computerized ball-tossing game was associated with greater relative left frontal activation (Harmon-Jones et al., 2009). In that study, the authors concluded that their left frontal activation finding was consistent with jealousy being associated with approach motivation. This finding was interpreted within long-standing research in human emotion that greater left-sided brain activity is associated with approach behavior and predominantly positive affect, while relative greater right-sided activity is associated with avoidance behavior and negative emotions (Davidson and Fox, 1982).
Like our male titi monkeys, Takahashi et al. (2006) found men who read about infidelity showed functional magnetic resonance imaging (fMRI) changes in the amygdala and the cingulate cortex (Takahashi et al., 2006). Takahashi et al. (2006) found that men who read statements about sexual infidelity had increased fMRI activation in the right amygdala (as well as other areas), while men who read statements about emotional infidelity had greater fMRI activation in the left and right cingulate cortex (as well as other areas). Unlike Takahashi and colleagues, who found right and left activation of the cingulate cortex with jealousy, Sun and colleagues (Sun et al., 2016) found that the left posterior cingulate gyrus fMRI activation was associated with romantic jealousy and the left anterior cingulate gyrus was associated with romantic happiness. Using EEG, fMRI and regional cerebral glucose metabolism PET/MRI methods allow us to visualize what areas of the brain are associated with behavior and social scenarios, but they do not allow us to know what types of receptors are being activated or what neurotransmitters are changing in the brain. Future research on jealousy using PET with specific radiotracers could allow us to measure changes in neurotransmitter availability and potentially in release in this model (Hostetler et al., 2017). While it is commonly assumed that lateralization is a human trait, brain (and behavior) asymmetries are not the exception but the norm, and can be found in all taxa of the animal kingdom (Gunturkun and Ocklenburg, 2017).

We found lower probabilities that our experimental condition affected plasma hormone concentrations of OT (65\%) or AVP (74\%), and a small effect size for AVP. Some human studies have found relationships between elevated plasma oxytocin levels and socially painful situations such as troubled romantic relationships (Taylor et al., 2010) or other types of relationship distress (Taylor et al., 2006), mainly in women. In contrast to women, higher levels of plasma vasopressin, but not oxytocin, were associated with relationship problems in men (Taylor et al., 2010). Although we did not find large differences in our peripheral measure of plasma OT and AVP peptide hormones, this does not mean that central nervous system changes in OT and AVP did not occur. Plasma and other peripheral measures of these peptide hormones are considered imperfect reflections of central nervous system levels (Freeman et al., 2016). An additional explanation for why we did not find a larger effect for plasma OT or AVP is the timing of when we collected blood samples from our subjects. While sampling blood following the 30 min FDG uptake period was reasonable timing to see effects of steroids such as testosterone and cortisol (Mendoza, 2017), it would almost certainly be past the peak timing to see effects of a behavioral stimulus on plasma oxytocin (Kenkel et al., 2012). Lastly, these blood samples also were taken after animals were sedated, so they do not represent "baseline" blood samples.

As predicted, there were positive associations between the jealousy condition and plasma steroid hormone concentrations of testosterone and cortisol. Testosterone concentrations were measurably higher in the jealousy condition, with a small to medium effect size. This increase is not surprising given testosterone's association with mating-related aggression 
(Wingfield et al., 1990; Wingfield, 2017). The "challenge hypothesis" predicts that androgens should respond acutely to social challenges, and then return to baseline in order to avoid adverse effects of steroids (Wingfield et al., 1990). This has been generally supported in the literature, including that on non-human primates (Bales et al., 2006) and humans (Archer, 2006). Cortisol was marginally higher during the jealousy condition ( $92 \%$ probability of a true effect), and it was significantly correlated with the time that the subject spent gazing at his pair mate and the stranger male, suggesting that this stimulus does constitute a social stressor (Mendoza, 2017). The increased time spent lip smacking during the jealousy condition compared to the control condition was possibly affiliative behavior directed toward his pair mate, an attempt to get her attention, or a form of self-soothing behavior. We did not tape the stimulus pair, so we do not know what specific behavior our subject was viewing. This is a limitation of the current study which should be corrected in future studies.

We also cannot say definitively that the subjects in our experiment experienced the emotion of "jealousy." Similarly, with humans we would need verbal confirmation that participants experienced this emotion. In particular, since the pair mate was separated from the stranger by a barrier, the stimulus may have been less potent for the subject than if the pair mate and stranger had full access to each other. The higher testosterone concentrations experienced by our male subjects when viewing their pair mate next to a stranger, as well as the positive correlations between duration of time spent looking across at them and both cortisol concentrations and FDG uptake in the lateral septum, do suggest that this situation may have been viewed as a challenge to the pair bond or sexual relationship. However, it is worth noting that the emotion we attribute to the subjects was not shown unambiguously through behavior.

A neural model of pair bonding in titi monkeys is beginning to coalesce, and the available evidence suggests both similarities and differences to the current, rodent-based model (Gobrogge and Wang, 2015; Numan and Young, 2016). When forming pair bonds, both prairie voles and titi monkeys recruit neural areas rich with oxytocin and/or vasopressin receptors and involved in social memory (such as the lateral septum), and dopaminergic areas involved in reward (such as the nucleus accumbens) (Bales et al., 2017). The involvement of these two systems suggests that the initial pair bond formation, and subsequent mating, serve both as learning and as positive reinforcing stimuli, involving the neural systems involved in other motivated behaviors (Tops et al., 2014). The maintenance phase of pair bonding is thought to be based on negative reinforcement; i.e., avoidance of aversive stimuli such as separation (Resendez et al., 2016), and to involve the opioid and dopamine systems as well. The lateral septum in titi monkey brain contains oxytocin receptors (Freeman et al., 2014), dopamine D1 receptors (Hostetler et al., 2017), dopamine D2 receptors (Bales, unpublished data), and both $\mu$ and $\mathrm{K}$ opioid receptors (Ragen et al., 2015). Thus, the lateral septum appears to be a hot-spot for both the formation and the maintenance of pair bonding in male titi monkeys. The neural substrates of primate pair bonding thus appear to involve the same principles and neurochemistry, but differing neural areas, as rodent pair bonding. Based on current mammalian phylogenies, it is likely that monogamy evolved multiple times (Lukas and Clutton-Brock, 2013), and it is therefore not surprising for the details of neurobiological mechanism to differ. Convergent evolution on nonapeptide mechanisms, however, seems likely given the outcomes of this and other studies.

Previous findings, as well as the present study, have suggested an important role for the lateral septum. Future research might focus on this area and particularly on interactions between the oxytocin, dopamine, and opioid systems, in order to continue dissecting the underpinnings of pair bonding in primates. Special attention will need to be paid to other potential differences from rodents, such as the longer time that it takes for primates to form a pair bond (Rothwell, unpublished data). Studying these neural substrates of social bonds may give us important clues with which to approach health and welfare problems such as addiction (Tops et al., 2014), autism (Anagnostou et al., 2014), and partner violence (Marshall, 2013). Finally, they may help inform us as to the evolutionary origin and maintenance of monogamy as a social system.

\section{AUTHOR CONTRIBUTIONS}

$\mathrm{KB}$, SM, and WM designed the study and obtained the funding. The animal experiments were carried out by $\mathrm{NM}$ and TS. SC and DR oversaw the methodology and analysis of the imaging data. DW performed the statistical analysis. $\mathrm{NM}$ and $\mathrm{KB}$ wrote the paper and all authors edited the final version.

\section{ACKNOWLEDGMENTS}

This research was supported by the National Institutes of Health (grants HD053555 and P51OD011107), and the Good Nature Institute. We also gratefully acknowledge the following for research assistance: Luana Griffin, Rebecca Larke, Carlos Almeida, Ben Ragen, and Bales lab undergraduate volunteers; Jaleh Janatpour and Kevin Theis for animal care; Dr. Angela Colagross-Schouten, Dr. Kari Christe, Dr. Laura Summers, and the veterinary staff for care and assistance with the PET scans; Vanessa Bakula, Sarah Grisso, Deborah Kent, and Research Services at CNPRC; Michelle Connell and Jennifer Fung at the Center for Molecular and Genomic Imaging; and Richard Larson and the Center for Imaging Sciences at UC Davis.

\section{SUPPLEMENTARY MATERIAL}

The Supplementary Material for this article can be found online at: http://journal.frontiersin.org/article/10.3389/fevo. 2017.00119/full\#supplementary-material 


\section{REFERENCES}

Anagnostou, E., Soorya, L., Brian, J., Dupuis, A., Mankad, D., Smile, S., et al. (2014). Intranasal oxytocin in the treatment of autism spectrum disorders: a review of literature and early safety and efficacy data in youth. Brain Res. 1580, 188-198. doi: 10.1016/j.brainres.2014.01.049

Aragona, B. J., Liu, Y., Yu, Y. J., Curtis, J. T., Detwiler, J. M., Insel, T. R., et al. (2006). Nucleus accumbens dopamine differentially mediates the formation and maintenance of monogamous pair bonds. Nat. Neurosci. 9, 133-139. doi: $10.1038 / \mathrm{nn} 1613$

Archer, J. (2006). Testosterone and human aggression: an evaluation of the challenge hypothesis. Neurosci. Biobehav. Rev. 30, 319-345. doi: 10.1016/j.neubiorev.2004.12.007

Bales, K. L., Arias del Razo, R., Conklin, Q. A., Hartman, S., Mayer, H. S., Rogers, F. D., et al. (2017). Titi monkeys as a novel non-human primate model for the neurobiology of pair bonding. Yale J. Biol. Med. 90, 373-387.

Bales, K. L., French, J. A., McWilliams, J., Lake, R. A., and Dietz, J. M. (2006). Effects of social status, age, and season on androgen and cortisol levels in wild male golden lion tamarins (Leontopithecus rosalia). Horm. Behav. 49, 88-95. doi: 10.1016/j.yhbeh.2005.05.006

Bales, K. L., Mason, W. A., Catana, C., Cherry, S. R., and Mendoza, S. P. (2007). Neural correlates of pair-bonding in a monogamous primate. Brain Res. 1184, 245-253. doi: 10.1016/j.brainres.2007.09.087

Barberis, C., and Tribollet, E. (1996). Vasopressin and oxytocin receptors in the central nervous system. Crit. Rev. Neurobiol. 10, 119-154. doi: 10.1615/CritRevNeurobiol.v10.i1.60

Beehner, J. C., and Bergman, T. J. (2017). The next step for stress research in primates: to identify relationships between glucocorticoid secretion and fitness. Horm. Behav. 91, 68-83. doi: 10.1016/j.yhbeh.2017.03.003

Bowler, C. M., Cushing, B. S., and Carter, C. S. (2002). Social factors regulate female-female aggression and affiliation in prairie voles. Physiol. Behav. 76, 559-566. doi: 10.1016/S0031-9384(02)00755-2

Breuner, C. W., and Hahn, T. P. (2003). Integrating stress physiology, environmental change, and behavior in free-living sparrows. Horm. Behav. 43, 115-123. doi: 10.1016/S0018-506X(02)00020-X

Buerkner, P. C. (2015). brms: Bayesian Regression Models using Stan. R Package Version 0.6.0. Muenster.

Buss, D. M. (2002). Human mate guarding. Neuro Endocrinol. Lett. S4, 23-29.

Carp, S. B., Rothwell, E. S., Bourdon, A., Freeman, S. M., Ferrer, E., and Bales, K. L. (2016). Development of a partner preference test that differentiates between established pair bonds and other relationships in socially monogamous titi monkeys (Callicebus cupreus). Am. J. Primatol. 78, 326-339. doi: 10.1002/ajp.22450

Caselli, C. B., Mennill, D. J., Gestich, C. C., Setz, E. Z., and Bicca-Marques, J. C. (2015). Playback responses of socially monogamous black-fronted monkeys to simulated solitary and paired intruders. Am. J. Primatol. 77, 1135-1142. doi: 10.1002/ajp.22447

Casto, K. V., and Edwards, D. A. (2016). Testosterone, cortisol, and human competition. Horm. Behav. 82, 21-37. doi: 10.1016/j.yhbeh.2016.04.004

Cohen, J. (2009). Statistical Power Analysis in the Behavioral Sciences. New York, NY: Taylor \& Francis.

Cubiciotti, D. D. I., and Mason, W. A. (1978). Comparative studies of social behavior in Callicebus and Saimiri: heterosexual jealousy behavior. Behav. Ecol. Sociobiol. 3, 311-322. doi: 10.1007/BF00296316

Davidson, R. J., and Fox, N. A. (1982). Asymmetrical brain activity discriminates between positive and negative affective stimuli in humans infants. Science 218, 1235-1237. doi: 10.1126/science.7146906

de la Horra, J., and Rodriguea-Bernal, M. (1999). The posterior predictive $p$-value for the problem of goodness of fit. Test 8, 117-128. doi: 10.1007/BF02595865

DeVries, A. C., DeVries, M. B., Taymans, S. E., and Carter, C. S. (1996). The effects of stress on social preferences are sexually dimorphic in prairie voles. Proc. Natl. Acad. Sci. U.S.A. 93, 11980-11984. doi: 10.1073/pnas.93.21.11980

Diaz-Munoz, S. L., and Bales, K. L. (2016). "Monogamy" in primates: variability, trends, and synthesis. Am. J. Primatol. 78, 283-287. doi: 10.1002/ajp.22463

Eisenberger, N. I. (2015). Social pain and the brain: controversies, questions, and where to go from here. Annu. Rev. Psychol. 66, 601-629. doi: 10.1146/annurev-psych-010213-115146
Ellis, C., and Weinstein, E. (1986). Jealousy and the social psychology of emotional experience. J. Soc. Pers. Relat. 3, 337-357. doi: 10.1177/0265407586033006

Everts, H. G., and Koolhaas, J. M. (1999). Differential modulation of lateral septal vasopressin receptor blockade in spatial learning, social recognition, and anxiety-related behaviors in rats. Behav. Brain Res. 99, 7-16. doi: 10.1016/S0166-4328(98)00004-7

Fernandez-Duque, E., Di Fiore, A., and De Luna, A. G. (2013). "Pair-mate relationships and parenting in equatorial saki monkeys (Pithecia aequatorialis) and red titi monkeys (Callicebus discolor) of Ecuador," in Evolutionary Biology and Conservation of Titis, Sakis, and Uakaris, eds L. M. Veiga, A. A. Barnett, S. F. Ferrari, and M. A. Norconk (Cambridge: Cambridge University Press), 295-302.

Fernandez-Duque, E., Valeggia, C. R., and Mason, W. A. (2000). Effects of pair-bond and social context on male-female interactions in captive titi monkeys (Callicebus moloch, Primates: Cebidae). Ethology 106, 1067-1082. doi: 10.1046/j.1439-0310.2000.00629.x

Ferris, C. F., and Delville, Y. (1994). Vasopressin and serotonin interactions in the control of agonistic behavior. Psychoneuroendocrinology 19, 593-601. doi: 10.1016/0306-4530(94)90043-4

Fisher-Phelps, M. L., Mendoza, S. P., Serna, S., Griffin, L. L., Schaefer, T. J., Jarcho, M. R., et al. (2016). Laboratory simulations of mate-guarding as a component of the pair-bond in male titi monkeys, Callicebus cupreus. Am. J. Primatol. 78, 573-582. doi: 10.1002/ajp.22483

Freeman, S. M., Samineni, S., Allen, P. C., Stockinger, D., Bales, K. L., Hwa, G. G., et al. (2016). Plasma and CSF oxytocin levels after intranasal and intravenous oxytocin in awake macaques. Psychoneuroendocrinology 66, 185-194. doi: 10.1016/j.psyneuen.2016.01.014

Freeman, S. M., Walum, H., Inoue, K., Smith, A. L., Goodman, M. M., Bales, K. L., et al. (2014). Neuroanatomical distribution of oxytocin and vasopressin 1a receptors in the socially monogamous coppery titi monkey (Callicebus cupreus). Neuroscience 273, 12-23. doi: 10.1016/j.neuroscience.2014.04.055

Gelman, A. (2013). Commentary: $p$-values and statistical practice. Epidemiology 24, 69-72. doi: 10.1097/EDE.0b013e31827886f7

Gelman, A., and Hill, J. (2007). Data Analysis Using Regression and Multilevel/Hierarchical Models. Cambridge: Cambridge University Press.

Gelman, A., Carlin, J. B., Stern, H. S., Dunson, D. B., Vehtari, A., and Rubin, D. B. (2014). Bayesian Data Analysis. Boca Raton, FL: CRC Press.

Gelman, A., Jakulin, A., Pittau, M. G., and Su, Y.-S. (2008). A weakly informative default prior distribution for logistic and other regression models. Ann. Appl. Statist. 2, 1360-1383. doi: 10.1214/08-AOAS191

Gelman, A., Meng, X.-L., and Stern, H. (1996). Posterior predictive assessment of model fitness via realized discrepancies. Stat. Sin. 6, 733-807.

Getz, L. L., McGuire, B., and Carter, C. S. (2003). Social behavior, reproduction and demography of the prairie vole, Microtus ochrogaster. Ethol. Ecol. Evol. 15, 105-118. doi: 10.1080/08927014.2003.9522676

Gobrogge, K., and Wang, Z. (2016). The ties that bond: neurochemistry of attachment in voles. Curr. Opin. Neurobiol. 38, 80-88. doi: 10.1016/j.conb.2016.04.011

Gobrogge, K., and Wang, Z. (2015). Neuropeptidergic regulation of pairbonding and stress buffering: lessons from voles. Horm. Behav. 76, 91-105. doi: 10.1016/j.yhbeh.2015.08.010

Gray, P. B., McHale, T. S., and Carre, J. M. (2017). A review of human male field studies of hormones and behavioral reproductive effort. Horm. Behav. 91, 52-67. doi: 10.1016/j.yhbeh.2016.07.004

Greenland, S., and Poole, C. (2013). Living with p-values: resurrecting a Bayesian perspective on frequentist statistics. Epidemiology 24, 62-68. doi: 10.1097/EDE.0b013e3182785741

Gunturkun, O., and Ocklenburg, S. (2017). Ontogenesis of lateralization. Neuron 94, 249-263. doi: 10.1016/j.neuron.2017.02.045

Guzman, Y. F., Tronson, N. C., Jovasevic, V., Sato, K., Guedea, A. L., Mizukami, H., et al. (2013). Fear-enhancing effects of septal oxytocin receptors. Nat. Neurosci. 16, 1185-1187. doi: 10.1038/nn.3465

Harmon-Jones, E., Peterson, C. K., and Harris, C. R. (2009). Jealousy: novel methods and neural correlates. Emotion 9, 113-117. doi: 10.1037/a0014117

Harrell, F. E., and Shih, Y. C. (2001). Using full probability models to compute probabilities of actual interest to decision makers. Int. J. Technol. Assess. Health Care 17, 17-26. doi: 10.1017/S0266462301104034 
Harris, C. R. (2003). A review of sex differences in sexual jealousy, including self-report data, psychophysiological responses, interpersonal violence, and morbid jealousy. Person. Soc. Psychol. Rev. 7, 102-128. doi: 10.1207/S15327957PSPR0702_102-128

Hazan, C., and Shaver, P. (1987). Romantic love conceptualized as an attachment process. J. Pers. Soc. Psychol. 52, 511-524. doi: 10.1037/0022-3514.52.3.511

Hedges, L. V. (2007). Effect sizes in cluster-randomized designs. J. Educ. Behav. Sci. 32, 341-370. doi: 10.3102/1076998606298043

Hinde, K., Muth, C., Maninger, N., Ragen, B. J., Larke, R. H., Jarcho, M. R., et al. (2016). Challenges to the pair bond: neural and hormonal effects of separation and reunion in a monogamous primate. Front. Behav. Neurosci. 10:221. doi: 10.3389/fnbeh.2016.00221

Hostetler, C. M., Hinde, K., Maninger, N., Mendoza, S. P., Mason, W. A., Rowland, D. J., et al. (2017). Effects of pair bonding on dopamine D1 receptors in monogamous male titi monkeys (Callicebus cupreus). Am. J. Primatol. 79, 1-9. doi: $10.1002 / a j p .22612$

Kenkel, W. M., Paredes, J., Yee, J. R., Pournajafi-Nazarloo, H., Bales, K. L., and Carter, C. S. (2012). Neuroendocrine and behavioural responses to exposure to an infant in male prairie voles. J. Neuroendocrinol. 24, 874-886. doi: 10.1111/j.1365-2826.2012.02301.x

Kleiman, D. G. (1977). Monogamy in mammals. Q. Rev. Biol. 52, 39-69. doi: $10.1086 / 409721$

Kruschke, J. (2014). Doing Bayesian Data Analysis: A Tutorial with R, JAGS, and Stan. New York, NY: Academic Press.

Kruschke, J. K., and Vanpaemel, W. (2015). "Bayesian estimation in hierarchical models," in The Oxford Handbook of Computational and Mathematical Psychology, eds J. Busemeyer, J. Townsend, Z. J. Wang, and A. Eidels. (Oxford: Oxford University Press), 279-299.

Leary, M. R. (2015). Emotional responses to interpersonal rejection. Dial. Clin. Neurosci. 17, 435-441.

Lee, J. J. (2011). Demystify statistical significance - time to move on from the $\mathrm{p}$ value to Bayesian analysis. J. Natl. Cancer Inst. 103, 2-3. doi: $10.1093 /$ jnci/djq493

Liu, Y., Curtis, J. T., and Wang, Z. (2001). Vasopressin in the lateral septum regulates pair bond formation in male prairie voles (Microtus ochrogaster). Behav. Neurosci. 115, 910-919. doi: 10.1037/0735-7044.115.4.910

Lukas, D., and Clutton-Brock, T. H. (2013). The evolution of social monogamy in mammals. Science 341, 526-530. doi: 10.1126/science.1238677

Maninger, N., Hinde, K., Mendoza, S. P., Mason, W. A., Larke, R. H., Ragen, B. J., et al. (2017). Pair bond formation leads to a sustained increase in global cerebral glucose metabolism in monogamous male titi monkeys (Callicebus cupreus). Neuroscience 348, 302-312. doi: 10.1016/j.neuroscience.2017.02.028

Manson, J. H. (1997). Primate consortships: a critical review. Curr. Anthropol. 38, 353-374. doi: $10.1086 / 204623$

Marshall, A. D. (2013). Posttraumatic stress disorder and partner-specific social cognition: a pilot study of sex differences in the impact of arginine vasopressin. Biol. Psychol. 93, 296-303. doi: 10.1016/j.biopsycho.2013.02.014

Mason, W. A. (1966). Social organization of the South American monkey, Callicebus moloch: a preliminary report. Tulane Stud. Zool. 13, 23-28.

Mason, W. A. (1974). Comparative studies of Callicebus and Saimiri: behaviour of male-female pairs. Folia Primatol. 22, 1-8. doi: 10.1159/000155614

Mason, W. A., and Mendoza, S. P. (1998). Generic aspects of primate attachments: parents, offspring and mates. Psychoneuroendocrinology 23, 765-778. doi: 10.1016/S0306-4530(98)00054-7

McElreath, R. (2015). Rethinking: Statistical Rethinking Book Package. Available online at: https://github.com/rmcelreath/rethinking

McGuire, B., and Getz, L. L. (1998). The nature and frequency of social interactions among free-living prairie voles (Microtus ochrogaster). Behav. Ecol. Sociobiol. 43, 271-279. doi: 10.1007/s002650050491

Mendoza, S. P. (2017). "Social stress: concepts, assumptions, and animal models," in Hormones, Brain, and Behavior, 3rd Edn., eds D. W. Pfaff and M. Joels (San Diego, CA: Elsevier, Inc.), 261-284.

Mendoza, S. P., and Mason, W. A. (1997). Attachment relationships in New World primates. Ann. N.Y. Acad. Sci. 807, 203-209. doi: 10.1111/j.1749-6632.1997.tb51921.x

Morey, R. D., Hoekstra, R., Rouder, J. N., Lee, M. D., and Wagenmakers, E.-J. (2015). The fallacy of placing confidence in confidence intervals. Psychon. Bull. Rev. 23, 103-123. doi: 10.3758/s13423-015-0947-8
Neal, A. M., and Edwards, K. M. (2015). Perpetrators' and victims' attributions for IPV: a critical review of the literature. Trauma Violence Abuse. doi: 10.1177/1524838015603551. [Epub ahead of print].

Numan, M., and Young, L. J. (2016). Neural mechanisms of mother-infant bonding and pair bonding: similarities, differences, and broader implications. Horm. Behav. 77, 98-112. doi: 10.1016/j.yhbeh.2015.05.015

Ophir, A. G., Wolff, J. O., and Phelps, S. M. (2008). Variation in neural VlaR predicts sexual fidelity and space use among male prairie voles in semi-natural settings. Proc. Natl. Acad. Sci. U.S.A. 105, 1249-1254. doi: $10.1073 /$ pnas.0709116105

Palombit, R. A. (2014). Sexual conflict in nonhuman primates. Adv. Stud. Behav. 46, 191-280. doi: 10.1016/B978-0-12-800286-5.00005-5

Phillips, K. A., Bales, K. L., Capitanio, J. P., Conley, A., Czoty, P. W., 't Hart, B. A., et al. (2014). Why primate models matter. Am. J. Primatol. 76, 801-827. doi: 10.1002/ajp.22281

Poletti, M., Perugi, G., Logi, C., Romano, A., Del Dotto, P., Ceravolo, R., et al. (2012). Dopamine agonists and delusional jealousy in Parkinson's disease: a cross-sectional prevalence study. Mov. Disord. 27, 1679-1682. doi: $10.1002 / \mathrm{mds} .25129$

Quene, H., and Van Den Bergh, H. (2004). On multi-level modeling of data from repeated measures designs: a tutorial. Speech Commun. 43, 103-121. doi: 10.1016/j.specom.2004.02.004

Ragen, B. J., and Bales, K. L. (2013). "Oxytocin and vasopressin in non-human primates," in Oxytocin, Vasopressin and Related Peptides in the Regulation of Behavior, eds. E. Choleris and M. Kavaliers (Cambridge: Cambridge University Press), 288-306.

Ragen, B. J., Freeman, S. M., Laredo, S. A., Mendoza, S. P., and Bales, K. L. (2015). $\mu$ and $\mathrm{K}$ opioid receptor distribution in the monogamous titi monkey (Callicebus cupreus): implications for social behavior and endocrine functioning. Neuroscience 290, 421-434. doi: 10.1016/j.neuroscience.2015.01.023

Resendez, S. L., Keyes, P. C., Day, J. J., Hambro, C., Austin, C. J., Maina, F. K., et al. (2016). Dopamine and opioid systems interact within the nucleus accumbens to maintain monogamous pair bonds. Elife 5:e15325. doi: 10.7554/eLife.15325

Rilling, J. K., Winslow, J. T., and Kilts, C. D. (2004). The neural correlates of mate competition in dominant male rhesus macaques. Biol. Psychiatry 56, 364-375. doi: 10.1016/j.biopsych.2004.06.027

Sbarra, D. A., and Hazan, C. (2008). Coregulation, dysregulation, self-regulation: an integrative analysis and empirical agenda for understanding adult attachment, separation, loss, and recovery. Person. Soc. Psychol. Rev. 12, 141-167. doi: 10.1177/1088868308315702

Shakespeare, W. (1988). Four Tragedie: Hamlet, Othello, King Lear, Macbeth. Logan, IA: Bantam Books.

Sheehan, T. P., Chambers, R. A., and Russell, D. S. (2004). Regulation of affect by the lateral septum: implications for neuropsychiatry. Brain Res. Brain Res. Rev. 46, 71-117. doi: 10.1016/j.brainresrev.2004.04.009

Simmons, T. C., Balland, J. F., Dhauna, J., Yang, S. Y., Traina, J. L., Vazquez, J., et al. (2017). Early intranasal vasopressin administration impairs partner preference in adult male prairie voles (Microtus ochrogaster). Front. Endocrinol. 8:145. doi: 10.3389/fendo.2017.00145

Singewald, G. M., Rjabokon, A., Singewald, N., and Ebner, K. (2011). The modulatory role of the lateral septum on neuroendocrine and behavioral stress responses. Neuropsychopharmacology 36, 793-804. doi: 10.1038/npp.2010.213

Spence-Aizenberg, A., Di Fiore, A., and Fernandez-Duque, E. (2016). Social monogamy, male-female relationships, and biparental care in wild titi monkeys (Callicebus discolor). Primates 57, 103-112. doi: 10.1007/s10329-015-0489-8

Stan_Development_Team (2015). Stan Modeling Language User's Guide and Reference Manual. Stan Development team.

Stribley, J. M., and Carter, C. S. (1999). Developmental exposure to vasopressin increases aggression in adult prairie voles. Proc. Natl. Acad. Sci. U.S.A 96, 12601-12604. doi: 10.1073/pnas.96.22.12601

Sun, Y., Yu, H., Chen, J., Liang, J., Lu, L., Zhou, X., et al. (2016). Neural substrates and behavioral profiles of romantic jealousy and its temporal dynamics. Sci. Rep. 6:27469. doi: 10.1038/srep27469

Tabbaa, M., Paedae, B., Liu, Y., and Wang, Z. (2016). Neuropeptide regulation of social attachment: the prairie vole model. Compr. Physiol. 7, 81-104. doi: 10.1002/cphy.c150055

Takahashi, H., Matsuura, M., Yahata, N., Koeda, M., Suhara, T., and Okuba, Y. (2006). Men and women show distinct brain activations during 
imagery of sexual and emotional infidelity. Neuroimage 32, 1299-1307. doi: 10.1016/j.neuroimage.2006.05.049

Tardif, S., Bales, K., Williams, L., Moeller, E. L., Abbott, D., Schultz-Darken, N., et al. (2006). Preparing New World monkeys for laboratory research. ILAR J. 47, 307-315. doi: 10.1093/ilar.47.4.307

Taylor, S. E., Gonzaga, G. C., Klein, L. C., Hu, P., Greendale, G. A., and Seeman, T. E. (2006). Relation of oxytocin to psychological stress responses and hypothalamic-pituitary-adrenal axis activity in older women. Psychosom. Med. 68, 238-245. doi: 10.1097/01.psy.0000203242.95990.74

Taylor, S. E., Saphire-Bernstein, S., and Seeman, T. E. (2010). Are plasma oxytocin in women and plasma vasopressin in men biomarkers of distressed pair-bond relationships? Psychol. Sci. 21, 3-7. doi: 10.1177/09567976093 56507

Team, R. C. (2016). R: a Language and Environment for Statistical Computing. Vienna: R Foundation for Statistical Computing.

Tecot, S. R., Singletary, B., and Eadie, E. (2016). Why "monogamy” isn't good enough. Am. J. Primatol. 78, 340-354. doi: 10.1002/ajp.22412

Tops, M., Koole, S. L., IJzerman, H., and Buisman-Pijlman, F. T. (2014). Why social attachment and oxytocin protect against addiction and stress: insights from the dynamics between ventral and dorsal corticostriatal systems. Pharmacol. Biochem. Behav. 119, 39-48. doi: 10.1016/j.pbb.2013.07.015

Van Belle, S., Fernandez-Duque, E., and Di Fiore, A. (2016). Demography and life history of wild red titi monkeys (Callicebus discolor) and equatorial sakis (Pithecia aequoatorialis) in Amazonian Ecuador: a 12-year study. Am. J. Primatol. 78, 204-215. doi: 10.1002/ajp.22493
Wingfield, J. C. (2017). The challenge hypothesis: where it began and relevance to humans. Horm. Behav. 92, 9-12. doi: 10.1016/j.yhbeh.2016.11.008

Wingfield, J. C., Hegner, R. E., Duffy, A. M. Jr., and Ball, G.F. (1990). The 'challenge hypothesis': theoretical implications for patterns of testosterone secretion, mating systems, and breeding strategies. Am. Natl. 136, 829-846. doi: $10.1086 / 285134$

Winslow, J. T., Hastings, N., Carter, C. S., Harbaugh, C. R., and Insel, T. R. (1993). A role for central vasopressin in pair bonding in monogamous prairie voles. Nature 365, 545-548. doi: 10.1038/365545a0

Zucker, D. R., Schmid, C. H., McIntosh, M. W., D’Agostino, R. B., Selker, H. P., and Lau, J. (1997). Combining single patient (N-of-1) trials to estimate population treatment effects and to evaluate individual patient responses to treatment. $J$. Clin. Epidemiol. 50, 401-410. doi: 10.1016/S0895-4356(96)00429-5

Conflict of Interest Statement: The authors declare that the research was conducted in the absence of any commercial or financial relationships that could be construed as a potential conflict of interest.

Copyright (C) 2017 Maninger, Mendoza, Williams, Mason, Cherry, Rowland, Schaefer and Bales. This is an open-access article distributed under the terms of the Creative Commons Attribution License (CC BY). The use, distribution or reproduction in other forums is permitted, provided the original author(s) or licensor are credited and that the original publication in this journal is cited, in accordance with accepted academic practice. No use, distribution or reproduction is permitted which does not comply with these terms. 